MEI, II, Vol. 2, nº 3, pág. 127

MEI

II, vol. 2

$\mathrm{n}^{0} 3$

\title{
Teresa Andrés y la organización Cultura Popular: una propuesta de coordinación bibliotecaria
}

\author{
(1936-1938) \\ Romà Seguí i Francés \\ Jefe de Sección de Promoción Cultural \\ Institut Valencià de la Música \\ Generalitat Valenciana
}

\begin{abstract}
Resumen
Teresa Andrés Zamora es conocida por su actividad al frente de la Sección de Bibliotecas de Cultura Popular. Este trabajo describe las relaciones que se establecieron entre 05-12-2011 Teresa Andrés y Cultura Popular, tras hacerse cargo de las responsabilidades del Ministerio de Instrucción Pública.

\section{Palabras clave}

Cultura Popular; Andrés Zamora, Teresa; Zardoya, Concha; Vicéns de la Llave, Juan; Amigos de Cultura Popular; Rodríguez Moñino, Antonio.

Teresa Andrés Popular Culture and organization : A proposed coordination librarian (1936-1938) Abstract

Teresa Andrés Zamora is known for her activity as head of the Section of Libraries of Cultura Popular. This paper describes the relations established between Teresa Andrés and Cultura Popular, after taking over the responsibilities of the Ministry of Public Instruction.
\end{abstract}

\section{Keywords}

Cultura Popular; Andrés Zamora, Teresa; Zardoya, Concha; Vicéns de la Llave, Juan; Amigos de Cultura Popular; Rodríguez Moñino, Antonio.

\section{Introducción}

Sobre Teresa Andrés ha ido apareciendo mucha bibliografía en los últimos años. De ser una bibliotecaria prácticamente desconocida, que en contra de viento y marea habían rescatado del olvido Blanca Calvo, Alicia Girón y Ramón Salaberria, se ha pasado a estudiarla de una manera más extensa y sistemática. Es cierto que Teresa Andrés es conocida sobre todo por ser la bibliotecaria que llevó adelante la Sección de Bibliotecas de Cultura Popular, aunque también tenemos constancia de que desarrolló otras tareas a lo largo del período de nuestra última guerra civil. Esta acumulación de cargos hace sospechar cuanto menos la posibilidad de haber generado un mito que no se corresponde con la realidad.

En este artículo se pretende explicar, por un lado, las actividades que llevó adelante Cultura Popular y por otro, cuál fue la implicación de Teresa Andrés en el proyecto, puesto que se debe esclarecer el papel que jugó para no generar expectativas falsas. 


\section{Los inicios de Cultura Popular}

\subsection{El impulso de Cultura Popular}

Cultura Popular fue una organización afín al PCE creada con el objetivo de coordinar las manifestaciones culturales que iban a realizar las organizaciones y los partidos que integraban el Frente Popular (Andrés Zamora, Teresa, 1937). Nació en abril de 1936 tras la victoria de las elecciones, constituyéndose un Comité Nacional en el que estaban representadas algunas organizaciones juveniles de partidos y sindicatos.

La Sección de Bibliotecas se creó con la finalidad de montar bibliotecas obreras en los centros de las organizaciones políticas y sindicales. Esta práctica permitiría acercar la lectura pública a colectivos más desfavorecidos. La estructura de la Sección partía de una oficina central que coordinaba el préstamo de los lotes de libros y centralizaba las adquisiciones. Incluso se llegó a pensar en una escuela para bibliotecarios obreros, lo que indica que se conocía de buena tinta el proyecto de la Biblioteca-Escuela que estaba ensayando en esos momentos María Moliner en Valencia para enseñar a los maestros a gestionar las pequeñas bibliotecas que enviaban las Misiones Pedagógicas (García Ejarque, Luis, 2000, p. 189-195).

No obstante, Cultura Popular adquirió relevancia tras el golpe de Estado de julio de 1936. En ese momento la organización incauta el palacio de los condes de Revillagigedo, en la calle Sacramento, $n^{\circ}$ 1, una calle muy céntrica de Madrid, al lado del Ayuntamiento. Este será el domicilio de, entre otros, Teresa Andrés, Josep Renau, Antonio Deltoro y más tarde de Emili Gómez Nadal, siendo estos tres últimos colaboradores de la revista valenciana Nueva Cultura. Tomás García, quien tomaría las riendas de Cultura Popular tras Teresa Andrés, ya se encontraba trabajando en la organización (Aznar Soler, Manuel y Pérez i Moragón, Francesc, 2008, p. 397). Es importante hacer esta precisión, puesto que Teresa Andrés pasará a formar parte del equipo que trabajará con Josep Renau en el Ministerio de Instrucción Pública y Bellas Artes.

\subsection{Los fundadores de la Sección de Bibliotecas: Juan Vicéns de la Llave y Teresa Andrés}

La organización de la Sección de Bibliotecas de Cultura Popular descansó en sus inicios sobre dos facultativos: Juan Vicéns y Teresa Andrés. La trayectoria profesional de ambos era muy diferente. Juan Vicéns (Zaragoza, 1895 - Pekín, 1959) se había incorporado como funcionario interino en la Oficina Técnica de la Junta de Intercambio y Adquisición de Libros en 1933, siéndole encomendada la tarea de inspector de bibliotecas públicas municipales, lo que le obligó a trasladarse por diferentes poblaciones de todo el territorio español con el objetivo de evaluar las bibliotecas ya instaladas y los lugares donde se quería crear una.

Él había estudiado en Madrid, alojándose en la Residencia de Estudiantes en la misma época en que se encontraban Buñuel, García Lorca, Dalí o Pepín Bello. Después marchó a París a trabajar como librero en un establecimiento que abrió con León Sánchez Cuesta. Con la proclamación de la II República se propuso volver y pudo incorporarse como interino al Cuerpo Facultativo. 
Su trabajo como inspector fue ingente, ya que no sólo visitó las que dependían de la Junta de Intercambio y Adquisición de Libros, sino también algunas que pertenecían a las Misiones Pedagógicas, como consta en la memoria de actividades de 1934, en las provincias de Albacete, Ávila, Badajoz, Cáceres, Huesca, León, Lugo, Murcia, Orense, Oviedo y Teruel. Es importante retener estas fechas porque Vicéns llegó a conocer las bibliotecas obreras asturianas y en especial la de Castropol.

El movimiento bibliotecario asturiano había nacido de la mano de Vicente Loriente en 1922. Con la intención de crear una biblioteca popular circulante en Castropol, varios intelectuales asturianos firmaron un manifiesto que difundieron en un periódico local el 20 de octubre de 1921. El 3 de marzo de 1922 abrió la biblioteca con 158 volúmenes, incrementándose el número hasta más de mil en 1925. A partir del año siguiente se crearon bibliotecas filiales. Su funcionamiento dependió de la voluntad de los propios obreros y de la labor que desarrolló Vicente Loriente, ya que las bibliotecas no eran atendidas por bibliotecarios profesionales.

La Administración no se implicó en el proyecto hasta la creación en 1931 de Misiones Pedagógicas, que abasteció con lotes de 100 libros a las bibliotecas filiales. Pero los sucesos de octubre de 1934 en Asturias acabaron con la quema o la destrucción de las bibliotecas, que ya se les empezaba a considerar como la causa de todos los males. La Biblioteca Popular Circulante de Castropol fue expulsada de su sede, ocupándola el partido de derechas Acción Popular. Además, el Gobierno había empezado a clausurar en agosto de 1934 las bibliotecas de los centros obreros de toda España (Salaberría, Ramón, 2002a, p. 326-327).

Juan Vicéns de la Llave fue consciente de todo este proceso --la creación y destrucción de las bibliotecas obreras-- desde una óptica privilegiada: su trabajo como inspector de bibliotecas le había llevado a visitar un centenar de bibliotecas en los municipios más recónditos de la geografía española. La Junta de Intercambio y Adquisición de Libros no le había enviado a inspeccionar los establecimientos de las capitales de provincia, lo que le permitió conocer de primera mano la situación bibliotecaria existente en las zonas rurales y obreras. Por todo ello, no es extraño que en 1938 escribiese las siguientes líneas:

Los bibliotecarios oficiales ignoraban la mayor parte de las técnicas consideradas en todas las partes como esenciales, la clasificación por materias, por ejemplo, y no utilizaban más que la simple ordenación alfabética de autores; igualmente ignoraban las técnicas de organización del préstamo, que no se practicaba en ninguna biblioteca institucional. Es fácil darse cuenta de que estas lagunas afectaban, sobre todo, a los lectores de cultura media que no siempre conocían los nombres de los autores y simplemente solicitaban libros acerca de esta o aquella materia. En cuanto a los trabajadores, tras una jornada completa de trabajo, ¿cómo pueden beneficiarse de la biblioteca si el préstamo no existía?

Los bibliotecarios de carrera salían de la Facultad de Filosofía y Letras y por lo general eran muy reaccionarios, su vocación era sobre todo los trabajos de erudición (hablo de aquellos que tenían gusto por el trabajo). Al llegar a ser bibliotecarios, su ideal era ser destinados a una biblioteca llena de libros antiguos donde nadie les fuera a importunar, donde poder dedicarse con toda tranquilidad a sus investigaciones eruditas o a la siesta. El pensamiento de trabajar en una biblioteca popular les colmaba 
de horror. Los que no podían librarse de una de ellas, buscaban la manera de estar en la biblioteca lo menos posible, lo que les permitía impartir cursos en los colegios religiosos. De esta manera, con frecuencia, el verdadero bibliotecario era el conserje.

A los esfuerzos emprendidos para poner fin a este estado de cosas y transformar las bibliotecas hacia su verdadero objetivo -- a fin de cuentas la instrucción del pueblo-los altos funcionarios respondieron con un cínico sabotaje y la persecución sistemática de aquéllos que eran culpables de tales sacrilegios.

Hasta ese momento, ni de las reglas básicas para la redacción de los catálogos alfabéticos ordenados por nombre de autor, ni sobre la organización técnica de las bibliotecas se había publicado una sola línea en España; para cubrir estas carencias me puse a estudiar de cerca la cuestión y redacté un manual de clasificación por materias que estaba a punto de aparecer cuando estalló la guerra; estudié igualmente la organización del préstamo y el canje interbibliotecario, tema sobre el que decidí realizar la tesis doctoral. Esta tesis constaba de dos partes: la primera estudiaba la organización del préstamo y el canje y la segunda demostraba cómo, sobre la base de esta técnica, se podían organizar redes de bibliotecas regionales y nacionales canalizando una activa circulación de libros. Estudié especialmente lo que se había hecho en ese sentido en los Estados Unidos, Inglaterra, la URSS y en otros lugares del mundo. Pero cuando presenté la tesis, un profesor reaccionario que formaba parte del tribunal (este antiguo bibliotecario está ahora con Franco) me dijo que eso no era un tema de tesis; lo encontraba grosero y vulgarmente material. Si yo hubiera estudiado las bibliotecas en el siglo XV... Pero las bibliotecas modernas contemporáneas, ¡no, eso era inadmisible! Evidentemente, su instinto le decía que debía oponerse en la medida en que mi tesis era favorable a la instrucción de las masas. Tras muchas vacilaciones el tribunal aceptó, pero con una cierta piedad condescendiente. Un hecho curioso: presenté mi tesis en junio de 1936 y, un mes más tarde, la guerra me puso ante la necesidad de aplicar las teorías y las reglas que yo había expuesto (Vicéns de la Llave, Juan, 2002, p. 56-58).

Este análisis se había basado en la experiencia personal que había tenido como inspector de bibliotecas y como militante del PCE. Juan Vicéns había entrado en el Cuerpo Facultativo en 1933 como interino, después de haber trabajado como librero en París en un establecimiento --la Librairie Espagnole--que había abierto con León Sánchez Cuesta. Con casi cuarenta años había regresado a una España que pretendía modernizarse. Su análisis debía ser muy diferente del del resto de facultativos. Su experiencia vital lo alejaba de una concepción oscurantista de la vida y de la cultura. Por su librería habían pasado Louis Aragon, André Breton, Elsa Triolet o Paul Eluard. Si ya su en su estancia en la Residencia de Estudiantes había conocido lo más granado de la Edad de Plata española, en París contactará con los intelectuales de izquierda. Por estas razones es oportuno reflejar el punto de vista de Vicéns.

Su perspectiva va más allá de la que se proponen sus colegas de profesión. El es, ante todo, una persona cosmopolita y el retrato que realiza se corresponde con una realidad que se imponía.

El rechazo de muchos facultativos a cualquier tarea relacionada con la lectura pública venía acompañado de un desconocimiento real de las técnicas biblioteconómicas esenciales, como son las del préstamo domiciliario o la clasificación de los fondos. Es evidente que las oposiciones no estaban dirigidas a reclutar bibliotecarios que 
asumiesen la lectura pública como objetivo prioritario: las pruebas habían estado diseñadas para personas con una erudición brillante.

Por otra parte, la experiencia había demostrado que la voluntad de los obreros había conseguido mantener bibliotecas abiertas, a pesar de que carecieran de los conocimientos necesarios para gestionarlas de manera adecuada. Las cifras de préstamo así lo indicaban. Además, la mayoría de facultativos no estaba interesada en abandonar sus puestos de trabajo para fomentar la lectura pública entre la población más necesitada, sobre todo debido a un clasismo que se había ido asumiendo a lo largo de años. Este panorama era el que facilitaba la creación de Cultura Popular.

El perfil de Teresa Andrés nada tiene que ver con el de Vicéns, aunque comparte algunos episodios biográficos que deberían tenerse en cuenta. Es obvio que la familia de Teresa Andrés fomentó en todo momento su formación --ella era la primogénita-hasta lograr que obtuviera sus títulos universitarios. También lo es que consideraron que debía continuar con ella en Madrid matriculándose en los cursos de doctorado. El hecho de pertenecer a un grupo de élite --las mujeres universitarias-- se debió reforzar con su estancia en la Residencia de Señoritas, donde se extremaban las medidas para conseguir que las residentes obtuviesen una cultura y una posición acorde con los tiempos que se avecinaban.

Su trabajo en el Instituto-Escuela de Madrid bajo las órdenes de María de Maeztu le habría llevado a comprender los ideales de la Institución Libre de Enseñanza, asumiendo que la necesidad de una formación que se adecuase a la función que se debía desempeñar era el único camino para transformar España. Cabe recordar que Juan Vicéns de la Llave también había recalado en la Residencia de Estudiantes en la época en la que allí se encontraban Pepín Bello, Luis Buñuel, Salvador Dalí o Federico García Lorca.

Sin embargo, la Residencia de Señoritas, aunque se plantease como una institución paralela a la Residencia de Estudiantes, partía de un presupuesto fundamental: las mujeres que iban allí, aun perteneciendo a una burguesía provinciana, buscaban una formación que les había estado vedada. No se trataba de una institución que pretendiese dar una pátina de buena familia a las señoritas, puesto que lo que allí se intentaba era crear una élite de mujeres universitarias que pudiesen lograr la transformación de la sociedad.

Si eliminamos todos los condicionantes que la llevaron a ser de una manera determinada, Teresa Andrés puede parecer que pertenece al perfil de facultativo que tanto criticaba Vicéns: es decir, por un lado desarrolla su carrera profesional en el Museo Arqueológico de León y en el Palacio Nacional, establecimientos que tenían unas funciones patrimoniales evidentes y, por otro, no se dedica a investigar sobre la profesión y las nuevas técnicas biblioteconómicas, puesto que decide elaborar una tesis doctoral sobre la rejería española.

A simple vista parece que Teresa Andrés no podía pertenecer al colectivo de facultativos que quería transformar la profesión de forma eficaz. Juan Vicéns de la 
Llave, en calidad de inspector, o María Moliner, como encargada de la delegación valenciana de Misiones Pedagógicas, conocían a la perfección el terreno de la lectura pública e incluso se habían atrevido a presentar comunicaciones en el II Congreso Internacional de Bibliotecas y Bibliografía celebrado en Madrid y Barcelona en 1935. Sólo cabe pensar que Teresa Andrés, desde una perspectiva política y vital, en la que el convencimiento de cambiar la sociedad pasaba por la instrucción del pueblo, supo entender el papel de la lectura pública como estrategia de transformación.

\subsection{Los objetivos}

Con la irrupción de la guerra, Cultura Popular varió sus objetivos, ya que sólo con cubrir la lectura en los centros o en los ateneos de las organizaciones políticas y sindicales no era suficiente, sino también se debía abastecer de lotes de libros a los que luchaban en las trincheras o los que se encontraban en los hospitales de sangre. Según cuenta Teresa Andrés:

Para atender a estas necesidades, se organizó en Madrid un gran depósito de libros, en el que se hacían lotes circulantes de unos 120 volúmenes, con libros distintos según estuviesen destinados a centros políticos, hospitales o cuarteles. Se formaron al mismo tiempo dos equipos de catalogadores, que iban a las organizaciones que lo solicitaban para enseñar a los encargados de las bibliotecas la organización y manejo de las mismas. Se formó un tercer equipo encargado de organizar el servicio de lectura en los hospitales de sangre. A las pocas semanas estaba en marcha todo este engranaje y en septiembre se habían ya repartido en Madrid ciento noventa bibliotecas (Andrés Zamora, Teresa, 1937, p. 604).

En septiembre de 1936, se montó una campaña en la prensa para publicitar los objetivos y los logros de Cultura Popular. Los datos que se señalaban diferían de los que Teresa Andrés ofrecería un año después, como podremos comprobar. No obstante, el texto del breve merece la pena ser reproducido porque da algunas pistas sobre cómo presentaron en un principio la imagen de la organización.

\footnotetext{
Se han creado, con la ayuda de diversos editores y libreros de Madrid, doscientas cincuenta bibliotecas en los hospitales, cuarteles y distintos lugares del frente, cuya relación detallada se publica estos días en la prensa. En todos los pueblos recorridos por los equipos de propaganda se nota la misma apetencia de cultura. Por esta razón es necesario intensificar este servicio hasta conseguir crear una biblioteca en cada rincón de España y se reitera el llamamiento a todos los que puedan donar libros, los cuales deben ser remitidos a Sacramento, 1, o bien avisar al teléfono 24204 para que se pase a recogerlos $(A B C, 22.09 .1936$. p. 16).
}

Es decir, las bibliotecas se habían creado en principio para abastecer a los milicianos y los soldados que se encontraban luchando en las trincheras. Se trataba de acercar la cultura a aquellos que estaban defendiendo con sus vidas la República. Este hecho propagandístico, favorecido por los intelectuales afectos al Gobierno leal, tenía como objetivo demostrar que se buscaba el enaltecimiento de las tropas mediante la cultura. Las trincheras y los libros se iban a convertir en aliados ante el analfabetismo y la fuerza bruta que los sublevados fomentaban. 
Es fundamental entender que la propaganda cultural perseguía mostrar un Gobierno alejado de los desastres que provocaban las «hordas marxistas». Los intelectuales de renombre habían abrazado la causa republicana y ésta era una carta que a lo largo de todo el conflicto el Gobierno leal jugará para defender su imagen. Por otro lado, en el breve se indica que la labor de Cultura Popular va más allá de crear bibliotecas en el frente, los hospitales y los cuarteles, puesto que retoma la idea de las Misiones Pedagógicas, abundando en la necesidad de crear bibliotecas en cualquier rincón de la geografía española. La cultura se transforma en un arma de propaganda.

De forma paralela, la Federación Española de Trabajadores de la Enseñanza (FETE), organización sindical nacida en el seno de la UGT, formó el Batallón Félix Barzana, que estaba integrado en esencia por profesores que pertenecían a los tres niveles de enseñanza y por funcionarios del Ministerio de Instrucción Pública. La incorporación del campesinado a las trincheras había evidenciado que, pese a los esfuerzos de la II República por erradicar el analfabetismo, aún existían colectivos que requerían de una instrucción primaria. Esta iniciativa fue transformándose hasta crearse las Milicias de la Cultura mediante Decreto de 30 de enero de 1937, siendo ministro de Instrucción Pública el comunista Jesús Hernández (Gaceta de la República nº 33, de 02.02.1937).

Esta organización, que estaba provista de la estabilidad orgánica del Ministerio, funcionaba bajo las órdenes del mando militar que asignaba milicianos de la cultura según la ratio de analfabetos que componían las diversas unidades de combate y siguiendo los dictados de los comisarios. La función esencial de los milicianos de la cultura consistía en enseñar a los combatientes a leer, escribir y realizar las operaciones aritméticas básicas, aunque también se encargaban de facilitar la lectura y la adquisición de otros conocimientos mediante la gestión de pequeños lotes de libros --veinte volúmenes-- que se intercambiaban cada cierto tiempo.

La actividad bibliotecaria que desarrolló se podría contabilizar en mil bibliotecas creadas en hospitales y cuarteles y mil cuatrocientas dieciocho en los diferentes frentes. Sin embargo, esta tarea bibliotecaria no fue obra de Milicias de la Cultura, sino de Cultura Popular (García Ejarque, Luis, 2000, p. 217). Esta confusión es comprensible si no se toman en consideración los diferentes departamentos que en ese momento ya funcionaban. En el Ministerio de Instrucción Pública, que dirigía Jesús Hernández, se creó el Consejo Central de Archivos, Bibliotecas y Tesoro Artístico el 16 de febrero de 1937, en el cual se encontraba la Sección de Bibliotecas, que presidía Tomás Navarro Tomás ocupando el cargo de secretaria Teresa Andrés.

La Sección de Bibliotecas tenía la competencia exclusiva de la política bibliotecaria en todos sus ámbitos. Aunque Teresa Andrés, como después se explicará, a medida que asumía responsabilidades, tuvo que dejar la dirección directa de la Sección de Bibliotecas de Cultura Popular, siempre consideró que esta organización debía encargarse de la política bibliotecaria en todo lo referente a hospitales, cuarteles y frentes. El testimonio de la poetisa Concha Zardoya, que colaboró de manera activa en la sede valenciana de Cultura Popular, confirma la relación establecida entre Cultura Popular y Milicias de la Cultura: 
Al no estar cerca de las trincheras, no podíamos llevar a ellas los libros y prensa que requerían los soldados. Nos pusimos en contacto con los milicianos y Comisarios de Cultura de los frentes de Andalucía y de Aragón para solucionar el problema. José Manaut y la Sección de Bibliotecas [de Valencia] sugerimos -lográndolo- fabricar unas pequeñas bibliotecas ambulantes y transportables por el miliciano o delegado de cultura -que actuaría como bibliotecario y velaría por la conservación de los libros-, consistiendo en un cajoncillo rectangular de unos 80 centímetros, tapa con llave que servía como pupitre, correa lateral para cargarla sobre los hombros y sillín plegable que servía de base o de asiento. El invento fue todo un éxito y pocos batallones carecieron de él. José Manaut consiguió el carpintero que los fabricó y la suma necesaria para la empresa (Zardoya, Concha, 2002, p. 24-25).

\title{
2.4. La consecución de fondos durante los primeros días de la guerra
}

La presentación en prensa que se ha citado indica que Cultura Popular había recibido donaciones de editoriales y libreros y que intentaba fomentar la donación de particulares. Incluso Juan Vicéns de la Llave explicaba lo siguiente:

\begin{abstract}
Desde que obtuvo un local, Cultura Popular comenzó a trabajar. El Ministerio de Instrucción Pública y la Cámara Oficial del Libro le dieron su apoyo; los periódicos y la radio le han permitido difundir su propaganda gracias a la cual han afluido las donaciones de libros, procedentes de particulares o de editoriales. ¡Qué generosidad la de los que aportaron sus libros u ofrecieron su tiempo libre para leer a los heridos! A falta de estanterías los libros se amontonaban en todas partes, en la cocina, sobre las mesas, en el suelo; desde su recepción se les clasificaba en tres grupos: el primero comprendía los libros sin interés, pornográficos o de ideología fascista, que se enviaban al pilón para hacer con ellos pasta de papel; el segundo grupo lo componían los ejemplares destinados a la Biblioteca Central; y el tercer grupo que comprendía la mayor parte de los libros recibidos era destinado a las bibliotecas circulantes. Éstos estaban constituidos según una elección conforme a los deseos y a las necesidades expresadas por sus destinatarios; en impresos a propósito era redactada una lista que ayudaba fácilmente a los trabajos de inventario y registro; de esta manera, la biblioteca podía funcionar desde el momento en que se remitía (Vicéns de la Llave, 2000, p. 69).
\end{abstract}

No hay que dudar en ningún momento de la afluencia de donaciones, pero, por mucho que uno se imagine, cabe pensar que éste no era el único canal que servía para incrementar los fondos de Cultura Popular. Es más, el gran depósito de libros que se creó en Madrid se logró, sobre todo, a partir de las incautaciones de librerías y de los fondos modernos de las bibliotecas que habían abandonado los afectos a los sublevados en su huída. Es evidente que, si multiplicamos ciento veinte volúmenes por las ciento noventa bibliotecas que señalaba Teresa Andrés, se obtiene una cifra de veintidos mil ochocientos volúmenes, cantidad imposible de recoger en dos meses en una ciudad en guerra, por muchas donaciones que se realizaran.

Es cierto que Javier Lasso de la Vega, facultativo que fue a Sevilla para ponerse a las órdenes de Queipo de Llano, siendo nombrado en septiembre de 1936 jefe del Servicio de Lecturas para el Soldado en los Frentes y Hospitales, logró reunir en varios meses cerca de cincuenta mil volúmenes (García Ejarque, Luis, 2000, p. 237-239), empleando con toda seguridad el método de la incautación de las bibliotecas de los vencidos. 
Téngase en cuenta que durante los primeros días de la guerra civil fueron incautadas en la zona leal una buena cantidad de bibliotecas por los partidos políticos y las organizaciones sindicales, sobre todo las de aquellas personas que habían huido a la zona sublevada, dejando tras de sí todas sus pertenencias. Por poner un par de ejemplos, merece la pena indicar los casos de las bibliotecas de Finat y del editor valenciano Miguel Juan. En el primero, la Agrupación Socialista Madrileña incautó esta colección valiosísima, que estaba compuesta en gran parte por primeras ediciones de clásicos españoles de los siglos XVI y XVII.

La Junta Delegada de Protección del Patrimonio estuvo persiguiendo el rastro de la biblioteca Finat hasta el final de la contienda, emitiendo diferentes informes. La Agrupación Socialista Madrileña la había confiscado y nunca lo notificó a la Junta Delegada de Protección del Patrimonio de Madrid (Álvarez Lopera, José, 1982, v. II, p. 133). Este fondo no estaba destinado, por mucho que se quiera, a un colectivo de lectores que podía satisfacer sus demandas mediante una política de lectura pública.

El segundo caso quizá sea más rocambolesco, pero no por ello menos real. Miguel Juan era un editor y librero valenciano de derechas al que le fueron incautadas por alguna organización su biblioteca particular y su librería durante los primeros días de la guerra. Miguel Juan era afecto a los sublevados sin ningún tipo de dudas. El primer libro que, tras la entrada en abril de 1939 de las tropas nacionales en Valencia, imprimió la Tipografía Moderna --el establecimiento que había estampado la emblemática revista Hora de España-- fue el facsímil del poema de Calderón de la Barca Psalle et Sile prologado por Leopoldo Trénor Palavicino --uno de los fundadores de la Liga Católica valenciana a principios del siglo XX-- y Joaquín de Entrambasaguas --conocido falangista que se dedicó en Valencia a destruir las partidas de libros que obraban en poder de las imprentas--. Miguel Juan era el editor de este opúsculo.

Lo interesante de su caso es comprobar cómo se pudo lograr una doble incautación. Tras la derrota, y siguiendo la política de depuración de la lectura pública, las bibliotecas que habían pertenecido a agrupaciones políticas u organizaciones sindicales fueron enviadas a las bibliotecas provinciales --en Valencia cumplía estas funciones la Biblioteca de la Universidad-- con el objetivo de depurarlas y de controlar su difusión.

El resultado de esta estrategia fue que las bibliotecas de aquellas y las que pertenecían a los «rojos» pasaron a engrosar los fondos de la institución universitaria, de tal forma que la biblioteca del escritor Max Aub compartía espacio con la de Miguel Juan (Pérez Moragón, Francesc, 2008, p. 155-167). Sobre Max Aub no es necesario añadir nada, pues es notorio que acabó exiliado en México. Lo de Miguel Juan es más extraño, aunque no tanto. Con toda seguridad sus libros fueron incautados por una organización «roja»y, tras ser rescatados por los sublevados para aplicar los criterios de depuración, fueron considerados como lectura que requería la autorización de la Comisión de Cultura. Que se sepa, Miguel Juan nunca solicitó que le fuesen devueltos. 
Por tanto, la incautación de librerías y bibliotecas fue una práctica habitual. En referencia a Cultura Popular, cabe señalar que el acopio de tantos ejemplares --más de veinte mil-- en un mes escaso obliga a sospechar sobre este tipo de práctica. El testimonio de Antonio Rodríguez-Moñino así lo indica. Es cierto que el estudio biográfico que realizó su sobrino Rafael Rodríguez-Moñino (2002) adolece de cierto espíritu crítico, puesto que transcribe documentos redactados por su tío en momentos difíciles sin tener en cuenta las condiciones históricas en que se elaboraron.

El caso del informe que tuvo que presentar Antonio Rodríguez-Moñino al tribunal de depuración que debía juzgar su actuación en la recuperación del patrimonio bibliográfico y documental es evidente.

El informe lo redactó en prisión en 1939 con el objetivo de salvar su propia vida. Sin embargo, presenta algunos datos que pueden ser contrastados, dándonos una visión más o menos precisa de lo que pudo suceder. La descripción de Antonio RodríguezMoñino es la siguiente:

\begin{abstract}
Algo más difícil fue otro problema que se planteó y que revestía caracteres, a mi modo de ver, catastróficos. Vicéns [de la Llave] y Teresa Andrés eran los dirigentes de una organización, «Cultura Popular», destinada a distribuir periódicos y libros en los frentes y retaguardia. Esta organización era filial del Partido Comunista y había expoliado las librerías en busca de volúmenes. Ambos y [Tomás] Navarro Tomás como Presidente de la Comisión Gestora de Archivos estimaron necesario incautarse de un Convento en la calle del Sacramento para establecer en él un Depósito de Bibliotecas incautadas (Rodríguez-Moñino, Rafael, 2002, p. 84).
\end{abstract}

Es interesante constatar que cita a tres facultativos que formaban parte, como después se comprobará, de la Comisión Gestora del Cuerpo Facultativo de Archivos, Bibliotecas y Museos y más tarde del Consejo Central de Archivos, Bibliotecas y Tesoro Artístico. Juan Vicéns de la Llave y Teresa Andrés siempre tuvieron una implicación personal en el proyecto de la Sección de Bibliotecas y ambos militaban en el PCE. Por otro lado, se señala la anquiescencia de Tomás Navarro Tomás en la incautación de librerías para conseguir fondos para la organización. La estrategia tenía sentido en un momento en que todos --incluido Antonio Rodríguez-Moñino-basaban su discurso en facilitar el acceso al pueblo al patrimonio bibliográfico que habían atesorado la nobleza y la Iglesia a lo largo de siglos (Seguí, Romà, 2008).

No obstante, hay que entender que la postura de Antonio Rodríguez-Moñino partía de unos presupuestos diferentes a los de Teresa Andrés, Tomás Navarro Tomás y Juan Vicéns, puesto que su trabajo consistía en incautar bibliotecas con fondos valiosos para entregarlos en la Biblioteca Nacional de España con la intención de que pasaran a engrosar el patrimonio público del Estado, logrando que se permitiese el acceso a los investigadores.

No es momento de entrar aquí a evaluar la tarea que Rodríguez-Moñino llevó a cabo durante los primeros meses de la contienda, pero sí lo es el de considerar el por qué de las discrepancias que se generaron entre él y los tres facultativos, sobre todo a raíz de entender la biblioteca como un todo que debía preservar su unidad. Y ese será un 
punto de fricción que les debió llevar a algún enfrentamiento. En una carta a Tomás Navarro Tomás de fecha de 4 de septiembre de 1936, a la sazón presidente de la Comisión Gestora del Cuerpo Facultativo de Archivos, Bibliotecas y Museos, Antonio Rodríguez-Moñino se despedía con estas palabras:

\begin{abstract}
Lamento en el alma, después de la labor conjunta que hemos realizado durante mes y medio, tenerme que despedir de ustedes: circunstancias y actitudes ajenas que me hacen, sin embargo, separarme de Vds. con la satisfacción de que durante el tiempo que hemos estado juntos se ha podido realizar una labor de incautación que ha enriquecido nuestros depósitos bibliográficos nacionales extraordinariamente (Rodríguez-Moñino, Rafael, 2002, p. 87-88).
\end{abstract}

El texto en sí no tiene mayor importancia, puesto que sólo indica que Antonio Rodríguez-Moñino dejó las labores de incautación en contra de sus deseos. El mecanuscrito de la carta incluía además una anotación de su puño y letra en la que explicaba la causa:

Motivó esto último un criterio cerrado, opuesto al de Teresa [Andrés] y Vicéns [de la Llave] secundado por [Tomás] Navarro [Tomás] que querían depositar los libros no raros [en $]$ Cultura Popular, para que ella los distribuyera.

Es importante constatar que este enfrentamiento no se reflejase en los diferentes cuadernos que envió al Tribunal que debía depurar sus responsabilidades. Se debe tener en cuenta que, cuando Antonio Rodríguez-Moñino redactó su pliego de descargos, ya se debía saber quienes habían huido de España, lo que facilitaba emplearlos como objeto de sus iras y críticas. También es llamativo que no incluyese información sobre este punto en un informe tan detallado como el que realizó.

No hay que hacer muchas cábalas para reconstruir las diferentes posturas: Antonio Rodríguez-Moñino defendía la necesidad de considerar una biblioteca como un conjunto de títulos que se había ido gestando a lo largo del tiempo, de tal suerte que el conjunto total evidenciaba una serie de intereses que añadían al fondo una complejidad que era necesario estudiar.

En resumen, la imagen del bibliófilo se reflejaba tanto en el libro antiguo que coleccionaba como en el título contemporáneo que adquiría para su ocio. Teresa Andrés, que había trabajado en el Palacio Nacional con libros raros y curiosos, sabía diferenciar los fondos patrimoniales antiguos, pero ante la tesitura de la guerra civil y la necesidad de garantizar los envíos de lotes en Cultura Popular, debió optar por separar aquellos fondos que no se consideraban de manera explícita como patrimoniales --es decir, libros en aquel momento modernos-- para abastecer el depósito de la organización.

Un detalle interesante, que no debe pasar desapercibido, es el testimonio de Emili Gómez Nadal, que se asombraba de la cantidad de libros en otros idiomas que existía en el depósito de Cultura Popular (Aznar Soler, Manuel y Pérez i Moragón, Francesc, 2008, p. 397), lo que abunda en indicar la procedencia de las bibliotecas. La postura de Antonio Rodríguez-Moñino se puede compartir sin lugar a dudas, puesto que 
entiende un legado con un sentido digamos archivístico --es el resultado de la acción de diferentes personas a lo largo de sus vidas--. Pero las necesidades planteadas por Cultura Popular también son comprensibles en un marco histórico como el de la guerra civil.

Pero lo que pudo ser una práctica habitual durante los primeros días de la guerra tendió a desaparecer a medida que el Gobierno tomó las riendas de la situación. El nombramiento en septiembre de 1936 de Jesús Hernández como ministro de Instrucción Pública y Bellas logró generar unas expectativas que se tradujeron en una normalización de la vida cultural. Josep Renau apoyó Cultura Popular, consiguiendo que se consolidase el proyecto.

En 1937 empezó a funcionar la asociación denominada Amigos de Cultura Popular, que se encargó de recaudar fondos para el sostenimiento de ésta, de tal suerte que desaparecieron las partidas presupuestarias del Ministerio de manera paulatina hasta normalizar el funcionamiento basándose en las cuotas de los asociados.

\subsection{El testimonio de Concha Zardoya}

La poetisa Concha Zardoya había nacido en Valparaíso (Chile) en 1914. En 1932 se instaló en Madrid, donde empezó a estudiar Filosofía y Letras en la Universidad Central de Madrid. El inicio de la guerra interrumpió sus estudios. Se sabe que se trasladó a Valencia en plena guerra. Su testimonio es muy relevante, en tanto que describe la actividad de la delegación valenciana de Cultura Popular, una vez que Teresa Andrés y Juan Vicéns de la Llave, debido a los cargos que ocupaban, habían dejado de actuar como dirigentes exclusivos de la Sección de Bibliotecas.

Por otro lado, su interpretación sobre el papel que había asumido Cultura Popular en sus inicios merece tenerse en cuenta para entender con perspectiva el giro que se efectúa en el ámbito de la lectura pública con la llegada al Ministerio de Instrucción Pública y Bellas Artes del comunista Jesús Hernández y todo su equipo. Este hecho es consustancial para comprender cómo se reinterpretan ciertas instituciones republicanas --las Misiones Pedagógicas en concreto-- por los militantes del PCE, puesto que su lectura se ciñe a los postulados frentepopulistas (Aznar Soler, Manuel, 2008).

Con motivo de un homenaje al pintor José Manaut Viglietti, quien dirigió la delegación valenciana, escribió unas páginas en las que describió de forma somera su implicación en Cultura Popular.

Pero la enseñanza sufrió un duro golpe con la Guerra Civil. Muchos de los estudiantes universitarios se vieron forzados a ingresar en los ejércitos de ambas zonas y numerosas escuelas no pudieron funcionar por falta de maestros. Los intelectuales -en la zona republicana- se agruparon en la «Alianza de Intelectuales Antifascistas para la Defensa de la Cultura» (AIADC). Los universitarios se agruparon en la FUE, en la FUHA [Federación Universitaria Hispanoamericana] y en «Cultura Popular», entidad que desde el comienzo de la contienda nació en Madrid para integrar en sí las funciones de las Misiones Pedagógicas y extender su obra a los frentes de batalla, a los hospitales de sangre, a las fábricas, a los centros obreros, etc. Su labor primordial 
era, sin embargo, dotar de prensa y pequeñas bibliotecas a combatientes y trabajadores, para su formación cultural, información o entretenimiento. «Cultura Popular»-con este propósito- atraía a intelectuales, poetas y estudiantes que no sólo distribuían libros y periódicos sino que celebraban recitales, charlas, actuaciones teatrales, danzas, etc. Establecida en el palacete Revillajijedo de la calle Sacramento, pasaron por «Cultura Popular» escritores como Ramón Sénder, poetas como Rafael Alberti, Emilio Prados y Arturo Serrano Plaja, además de jóvenes que empezaban a escribir y a publicar. De manera constante, trabajaron por un tiempo José María Quiroga Pla, el profesor Emilio Gómez Nadal, junto a los maestros Justo Escobar y Enrique González. Muchos jóvenes de ambos sexos -«anónimos» hoy para míayudaron en arduas tareas menores pero sustanciales (Zardoya, Concha, 2002, p. 2122).

Concha Zardoya planteaba un paralelismo entre Misiones Pedagógicas y Cultura Popular, suponiendo que esta última asumió las funciones de la primera. No obstante, Cultura Popular había buscado un ámbito de desarrollo diferente, puesto que se centraba en organizaciones políticas y sindicales y en todo aquello que se refería al frente de batalla, aunque en algún momento se había señalado que sería necesario abastecer de bibliotecas a todas las poblaciones. Esto no significa que no conservase una estructura de funcionamiento que había dado sus frutos, en tanto que empleaba una estrategia semejante basada en el envío de lotes de libros y en la celebración de actos culturales como las representaciones teatrales o los recitales poéticos. De hecho, años después Josep Renau recordaba:

Lo habíamos pensado y debatido mucho, y no estábamos de acuerdo con las concepciones y orientaciones krausistas, imbuidas de germanismo idealista, de la Institución Libre de Enseñanza y de sus Misiones Pedagógicas, que constituían la ideología oficiosa de la época. Con todo el bien que antaño habían deparado a España, en las nuevas condiciones las considerábamos totalmente insuficientes, pues en sus más generosas actitudes y acciones didácticas, asumían un claro elitismo paternalista, que consideraba a la masa campesina y popular poco menos que un "saco vacío" que había que "llenar" con versiones "de izquierda" de la cultura de nuestro Siglo de Oro muy particularmente (Renau, Josep, 2007).

Es decir, se trataba de transformar el contenido de las Misiones Pedagógicas, ya que en los momentos que sucedieron a la sublevación de julio de 1936 no tenía sentido repetir los mismos mensajes que se habían difundido en tiempos de paz. La agitación como arma de propaganda exigía retomar los esfuerzos y cambiar el significado que se pretendía expresar. Cultura Popular nacía de la experiencia de las Misiones Pedagógicas, pero no recuperaba su mensaje.

Pero el testimonio de Concha Zardoya es sobre todo relevante porque informa sobre la constitución y la actividad de la sede valenciana de Cultura Popular en la calle de la Paz.

Cuando el cerco de la capital obligó al Gobierno a trasladarse a Valencia, «Cultura Popular» se sintió obligada a proseguir su labor en la nueva zona de levante y principalmente del frente de Teruel. Así abrió una nueva sede en la ciudad valenciana. Teresa Andrés Zamora -por entonces Secretaria de Bibliotecas del Consejo Central de Archivos, Bibliotecas y Tesoro Artístico- y Tomás García -Secretario General de la sede madrileña de «Cultura Popular»- fundaron en el mes de enero de 1937 el nuevo centro de Valencia, que nació de modo diferente. Se procedió a invitar a los secretarios 
culturales de todos los partidos políticos, con el fin de que todo el Frente Popular colaborara en las labores de la institución, tan valiosa para la guerra como para la paz. La primera reunión se efectuó en un local de Izquierda Republicana y en el mes de enero de 1937. Cada partido político, la Alianza de Intelectuales y las asociaciones estudiantiles enviaron un representante al acto de fundación, presidido naturalmente por Tomás García. Se distribuyeron los cargos según la preparación y preferencias de los delegados. Fue elegido secretario general de la institución el representante de la Alianza de Intelectuales, José Manaut Viglietti, pintor y profesor de Instituto. No recuerdo el nombre de los otros miembros ni de las secciones que les otorgaron. A mí me correspondió organizar y dirigir la sección de Bibliotecas, representando a la Federación Universitaria Hispanoamericana (FUHA) por ser estudiante de Filosofía y Letras de la Universidad de Madrid y haber trabajado ya en la mencionada sección de bibliotecas de la sede madrileña. Se nos concedió para nuestras funciones un local abandonado de la calle de la Paz y fue difícil tarea ponerlo en condiciones. La labor de limpieza previa me correspondió a mí -como única mujer del consejo directivo- y a José Manaut la adquisición de un mínimo amueblado y utillaje para empezar a actuar, solicitando la cooperación de instituciones y autoridades. Ardua labor la suya y así empezamos con la mayor pobreza, salvo polvo y nicotina por todas partes. Cuando obtuve los primeros libros -donados por la Distribuidora de Publicaciones del Ministerio de Instrucción Pública, algunas editoriales, centros de cultura inactivos, «yacimientos» de bibliotecas destinadas al fuego de cocinas y estufas, etc., tuve que ordenarlos en cajas de cartón a manera de estantes... José Manaut se afanó en conseguir ayudas de toda índole, con una decisión y constancia heroicas. Al fin tuvimos estanterías de pino para el depósito de libros, unos pocos muebles usados y maltrechos -mesas y sillas- para las oficinas y, finalmente, mostradores y «decentes» librerías para la Biblioteca Circulante que se instaló en beneficio de la ciudadanía valenciana, carente de centros y programas culturales. Para favorecer esta biblioteca, José Manaut logró constituir después la «Asociación de Amigos de "Cultura Popular"», porque había cesado la aportación económica del Ministerio de Instrucción Pública, y había que encontrar nuevas fuentes para su sostenimiento (Zardoya, Concha, 2002, 22-23).

El relato de Concha Zardoya, con toda seguridad impreciso por el tiempo transcurrido entre los acontecimientos y su redacción, nos ofrece un panorama interesante. En primer lugar, presenta a una Teresa Andrés que ya no es la encargada directa del proyecto, debido a sus responsabilidades en el Ministerio --por la fecha que indica aún no era secretaria de la Sección de Bibliotecas del Consejo Central de Archivos, Bibliotecas y Tesoro Artístico, aunque debía estar preparando junto a Renau la estructura orgánica de la Dirección General de Bellas Artes-- y a Tomás García como responsable de la sede madrileña. Concha Zardoya había colaborado en Madrid con Cultura Popular en los primeros días de la guerra y debía desconocer el origen de la organización, que respondía al intento de integrar las diferentes entidades que formaron el Frente Popular. Pero su apostilla confirma que durante esa primera época los que colaboraron en Madrid de manera efectiva militaban o eran simpatizantes del PCE.

Para la fundación de la sede valenciana se contó con todos los partidos y organizaciones que integraban el Frente Popular. De entre todos los delegados se eligió como secretario general a José Manaut Viglietti, de la Aliança d'Intel·lectuals per la Defensa de la Cultura [AIDCV]. Concha Zardoya se encargó de la Sección de Bibliotecas. El acto de inauguración de la sede fue presidido por Tomás García. 


\section{La actividad de Cultura Popular}

Cultura Popular fue una organización que llegó a tener dos delegaciones a lo largo de la contienda. Este hecho responde a una situación bélica evidente: el inicio del asedio a Madrid por los sublevados forzó a evacuar la capital con el objetivo de trasladar el Gobierno y la Administración central a Valencia. Esto sucedía a finales de 1936. Cultura Popular inauguró sede en Valencia en enero de 1937. Teresa Andrés y Juan Vicéns de la Llave también se encontraban en Valencia. Esta duplicidad de sedes obliga a separar en algunos casos las actividades que realizaron tanto una como otra, sobre todo porque la mayoría de datos que se tienen a partir de 1937 hacen referencia a la Central de Valencia.

En referencia a las actividades bibliotecarias, el grueso de las gestiones a partir de 1937 se centró en Valencia por dos razones básicas:

a) La Oficina de Adquisición de Libros y Cambio Internacional, servicio que coordinaba el sistema de lectura pública, no se trasladó de Valencia en ningún momento.

b) Teresa Andrés permaneció en Valencia como delegada del Ministerio de Instrucción Pública y Bellas Artes hasta 1938.

No obstante, durante el segundo trimestre de 1938 Cultura Popular retomará una campaña de creación de bibliotecas en Madrid. Con toda seguridad, es el canto de cisne de la organización.

\subsection{Las sedes}

\subsubsection{Madrid}

La primera sede que tuvo la organización en Madrid fue la del palacio de Revillagigedo en la calle Sacramento, 1. Es esta la dirección que consta en las comunicaciones que se enviaban a los diarios durante el año 1936 y buena parte de 1937. En diciembre de 1937 cambian de sede y ocupan parte de la Residencia de Estudiantes.

Durante los primeros meses de la guerra la Sección de Bibliotecas la formaban Teresa Andrés, Juan Vicéns de la Llave, Tomás García --llegó a ser secretario general-- y Arturo Aceves. En diciembre de 1937 figuran como miembros del Comité Técnico Directivo Óscar Antonio Súccar, en calidad de secretario, y Francisco Ribes, Carmela Iglesias, Ángel López Castro, Francisco Mora y Francisco Burgos Lecea, como vocales. Es interesante destacar que Carmela Iglesias, militante del PCE, también tendrá un cargo de responsabilidad --secretaria general-- en la Delegación Provincial de Madrid del Sindicato de Trabajadores en Archivos, Bibliotecas y Museos.

\subsubsection{Valencia}

La sede valenciana de Cultura Popular se encontraba en el número 23 de la calle de la Paz, la misma en la que estaba la Casa de la Cultura, a unos pasos del Ministerio de Instrucción Pública (Plaza de Ausiàs Marc, $n^{\circ}$ 1). Este local había pertenecido al 
Círculo de Bellas Artes y en aquellas fechas se encontraba abandonado. La estrategia de crear una nueva de sede en Valencia obedecía con toda seguridad al traslado del Gobierno. La evacuación de intelectuales y funcionarios de Madrid había empezado con los primeros bombardeos y Valencia se estaba conviertiendo en el centro político y cultural de la República.

Se sabe que la sede empezó a funcionar en enero de 1937. En una noticia aparecida el 3 del mismo mes en el diario valenciano Verdad, que era el órgano de propaganda conjunto del PCE y PSOE, codirigido por Max Aub y Josep Renau y en el que trabajaba como redactor Emili Gómez Nadal, se explicaban las tareas que había acometido la organización en Madrid, añadiendo que:

\begin{abstract}
Se realizan en la actualidad las primeras gestiones para constituir la Sección Valenciana de Cultura Popular. Esperemos que éstas tendrán el más rápido éxito. Todas las organizaciones y el pueblo todo de Valencia deben prestar la máxima atención y ayuda a una organización de este tipo., ya que la preocupación cultural no es una ficción levantada por nosotros, sino que es compartida por millares y millares de combatientes (Cultura Popular, 1937, p. 2).
\end{abstract}

El 13 de enero en una emisión radiofónica José Manaut Viglietti explicó las tareas que había llevado a cabo Cultura Popular en Madrid durante los primeros meses de la guerra. El 18 del mismo mes la Agence Espagne incluía una noticia, cuyo origen era Valencia, sobre la actividad de la organización, indicando que el Ministerio de Instrucción Pública y Bellas Artes daba apoyo a esta iniciativa (Agence Espagne, 1937a). Este punto es importante para entender el papel que ya estaba jugando Teresa Andrés dentro de la Administración, en tanto que había logrado que Cultura Popular adquiriese una naturaleza autónoma --era una organización creada sin el concurso del Estado-- que se beneficiase de la estructura orgánica del Ministerio. Ambas noticias confirman que la sede valenciana ya estaba empezando a funcionar.

El secretario general fue José Manaut Viglietti, la responsable de la Sección de Bibliotecas Concha Zardoya, el de propaganda Ángel Beltrán y el del servicio de prensa F. Salvador Aznar. Concha Zardoya, militante del PCE, también fue secretaria adjunta en la Delegación Provincial de Valencia del Sindicato de Trabajadores en Archivos, Bibliotecas y Museos.

\title{
3.2. Las actividades de propaganda
}

Uno de los lemas de Cultura Popular era «El fusil de HOY es garantía de la cultura de MAÑANA», y expresa de manera contundente el objetivo de la organización. A diferencia de Misiones Pedagógicas, que se había creado en 1931 en tiempos de paz, Cultura Popular nace con el impulso de la guerra civil. Pero no hay que olvidar que aquellas también surgieron con un objetivo claro, puesto que en el Decreto de creación, de 29 de mayo de 1931, se había incluido como finalidad un apartado denominado de «educación ciudadana» (art. 3.C), mediante el que se intentaba explicar los ideales democráticos de la República a los campesinos, abundando en la separación de poderes, la participación ciudadana y el papel de la Administración en la vida pública. 
Se trataba de transformar la mentalidad del campesinado para que abandonara las prácticas caciquiles que hasta la época habían dirigido sus destinos. Las Misiones Pedagógicas también tenían una orientación ideológica que no debe desdeñarse. La sublevación de julio de 1936 obligó a variar los presupuestos de las organizaciones, pero no a olvidarlos. La defensa de la cultura como un bien que había que preservar con las armas se basaba en los logros obtenidos por Misiones Pedagógicas. Cultura Popular no podía omitirlos e hizo una relectura basándose en la necesidad de plantear la lucha armada como la defensa de unos ideales. Para ello se comprometerá en diferentes actividades de propaganda que permitirán difundir su mensaje.

El 30 de marzo de 1937, con motivo de la apertura de la Central de Valencia, la Agence Espagne ofreció en su boletín la noticia siguiente:

L'organisation culturelle "Cultura Popular" ayant pris une importance nationale vient d'avoir sa Maison Centrale .à Valence. Cette organisation avait été fondée quelques mois avant la guerre. Elle s'était à peine mise au travail que la guerre éclata. Le premier moment de confusion passé, "Cultura Popular" se remit au travail, s'adaptant aux besoins de la guerre. C'est ainsi qu'en pleine guerre, elle fonda, à Madrid et dans les environs, plus de 600 bibliothèques dont 200 spécialisées dans les livres de technique militaire. Chaque jour, plus de 1.000 volumes et plus de 30.000 journaux, en plus des revues hebdomadaires, étaient distribués. D’autre part, pendant les deux premiers mois, plus de 100.000 volumes ont été recueillis et distribués. En outre, "Cultura Popular" organisait tous les jours des séances de théâtre et de cinéma pour les blessés, pour les miliciens et pour les enfants dans les lieux mêmes où ceux-ci se trouvaient. Un camion aménagé cet effet parcourait les fronts. Au cours d'un voyage de 3 ou 4 jours, plus de 50.000 revues et brochures étaient distribuées. Le camion possédait une installation pour projections cinématographiques, un poste de T.S.F. et un phonographe. Les rapports étroits qui naquirant entre “Cultura Popular' et les Commissaires politiques finirent par la rendre absolument indispensable pour ces derniers auxquels elle fournissait les matériaux nécessaires à leur travail (Agence Espagne 1937b).

La noticia, aun sabiendo que contiene un grado de propaganda importante, proporciona suficiente información para comprender la cantidad de actividades que se llevaban a cabo dentro de la organización. Por otro lado, el paralelismo con las Misiones Pedagógicas parece evidente. Como mínimo, se quería publicitar que la labor de Cultura Popular seguía sus pasos.

La insistencia en recalcar que los tres colectivos más beneficiados eran los heridos, los milicianos y los niños implicaba que los objetivos de actuación habían variado. La lucha contra el analfabetismo se priorizaba en los colectivos más frágiles: los que batallaban y los niños. El Gobierno lanzaba así un mensaje que lo presentaba preocupado por evidenciar que la cultura era la base sobre la que se había generado el conflicto. El ideal ilustrado de transformar el individuo mediante la educación era un principio vigente. 


\subsection{El reparto de periódicos}

Una de las actividades fundamentales de Cultura Popular durante su primer año fue el de la distribución de diarios en los frentes, hecho que suele pasar desapercibido, pero que indica, entre otras cosas, la necesidad de difundir de manera rápida los mensajes que se generaban para mantener la moral en las trincheras. Incluso se debe añadir que la estrategia de difundir prensa se fundamentaba en la necesidad de recibir noticias en un momento tan extremo como éste.

Esta postura, la de defender la publicación de diarios como medio de información y como herramienta de propaganda, era compartida por otros colectivos como la Federación Anarquista Ibérica, quienes en el Pleno Regional celebrado en Valencia entre el 29 de noviembre y el 1 de diciembre de 1936 habían discutido sobre la necesidad de crear una nueva editorial.

El grupo Ética de Gandía defendió que lo que se reclamaba era la información sobre lo que sucedía, no teniendo tiempo para leer monografías u opúsculos, ya que «el público no lee demasiado a causa de lo que absorbe su atención la lucha del momento». Incluso el representante de la Federación de Anarquistas Portugueses añadió que lo importante era que la cultura --entiéndase aquí como propaganda-debía traducirse en «camiones con altavoces, imprentas y bibliotecas ambulantes, octavillas y manifiestos, etc., etc.» (Navarro, Francisco Javier, 2002, p. 152-153). Esta propuesta chocaba de lleno con Cultura Popular por una razón esencial. Las campañas de Cultura Popular estaban dirigidas por facultativos profesionales que conocían los planteamientos bibliotecarios.

La campaña de reparto de prensa de Cultura Popular en el área de Madrid se encontró con diferentes obstáculos a lo largo de toda la contienda. El primero fue la reducción de los medios de transporte en noviembre de 1936, lo que imposibilitaba que Cultura Popular hiciese el reparto en los cuarteles, hospitales y organizaciones políticas y sindicales. Ante esta tesitura, se optó por continuar manteniendo el servicio, rogando a los beneficiarios que enviaran a un representante para que se presentara para recoger los ejemplares $(A B C, 18.11 .1936$, p. 15). De esta medida se exceptuaban los frentes, a los que acudían con una furgoneta en la que constaba el rótulo de Cultura Popular.

Por las cifras que ofreció la organización, se llegaron a distribuir diariamente 2.200 ejemplares de periódicos. Además, se incluían unos 4.000 ejemplares de los semanarios de Socorro Rojo Internacional y Ahora (ABC, 08.02.1938, p. 5). Este servicio de distribución de prensa quedo cancelado en febrero de 1938, debido a que carecía de cualquier medio de transporte que facilitase el reparto $(A B C, 10.02 .1938, \mathrm{p}$. $4)$.

En el caso de la delegación de Valencia el servicio de reparto de prensa estuvo más activo que en Madrid y no es de extrañar. Con el traslado del Gobierno a Valencia a finales de 1936, la sede valenciana obtuvo el respaldo eficaz del Ministerio de Instrucción Pública y Bellas Artes. En la retaguardia, sin una situación de asedio que 
obligaba a replantear los servicios de forma constante, la organización podía funcionar con mayor eficacia. De hecho, según consta en las estadísticas del tercer trimestre de 1937 se habían distribuido un total de 177.437 ejemplares: 147.025 de prensa local, 26.932 de prensa extranjera y 3.480 revistas (Cultura Popular, $\mathrm{n}^{\mathrm{o}}$ 1, noviembre 1937 , p. 2).

\subsection{Las actividades culturales}

La actividad propagandística de Cultura Popular también se centró en otros ámbitos como fueron las emisiones de radio o los concursos de periódicos murales. Ambas actividades venían anunciadas en la prensa con el objetivo de difundirlas de forma masiva. Aunque la mayoría de estas actividades se realizaban desde la Delegación de Valencia, tuvieron su eco en la prensa madrileña, que dedicó diferentes breves para publicitarlas.

En referencia a los periódicos murales, en julio de 1938 se celebró un concurso uno en el que participaron unidades militares, escuelas y organizaciones político-sindicales. Hubo algunos escritos en catalán. Carles Salvador, con motivo de la exposición, leyó algunos poemas y en la clausura intervino Emili Buïl (Blasco, Ricard, 1979, p. 151).

Las emisiones de radio se celebraban en los micrófonos de Unión Radio de Valencia y tenían lugar los sábados a las seis y media de la tarde. Los programas estaban compuestos por diferentes apartados:

a) Explicación sobre el funcionamiento de alguna de las actividades de Cultura Popular. Es decir, se hablaba sobre el reparto de prensa, propaganda o bibliotecas.

b) Lectura de poemas. Por ejemplo, Juan Gil-Albert recitó una traducción de un poema de Puskhin y Concha Zardoya un poema de Alberti.

c) La Sección de Música. Unas veces se escuchaban piezas de autores como Mozart, Tchaikovski, Borodin o Rimski-Korsakov y otras se acompañaba la audición con el comentario de un experto, como sucedió en la emisión que colaboró Eduardo López Chavarri explicando la biografía de Beethoven.

Es interesante destacar que durante las emisiones del 13, 20 y 27 de noviembre de 1937 Teresa Andrés leyó sus Indicaciones para la organización de frentes, hospitales y cuarteles. Pero no siempre las emisiones de Cultura Popular se realizaban desde Unión Radio de Valencia. Hay constancia por lo menos de una emisión realizada desde Unión Radio de Madrid. Esta emisión se realizó para diferentes colectivos de diversas nacionalidades como la catalana, vasca, valenciana, polaca, francesa, alemana o italiana (ABC, 24.12.1936, p. 6).

Pero la actividad que generró mayor popularidad en la sede valenciana fue la organización de exposiciones. La primera de la que se tiene noticia es la que sirvió para que los ciudadanos contemplaran el busto de Dolores Ibárruri, la Pasionaria, que había realizado Vitorio Macho. Este escultor había sido evacuado de Madrid con otros intelectuales, instalándose en la Casa de la Cultura, institución en la que figuró Emili 
Gómez Nadal como uno de los secretarios del comité ejecutivo. De hecho, según rezaba en la propaganda que apareció el 22 de octubre de 1937 en el diario Verdad, la Casa de a Cultura había inaugurado la exposición con el busto de la Pasionaria el día anterior en los locales de Cultura Popular. Éstos casi se encuentran enfrentados en la misma calle de la Paz. El 3 de octubre finalizó la exposición.

Merece mención aparte la Primera Exposición de Dibujo Infantil Antifascista. Este concurso estaba pensado para que los niños describieran mediante dibujos su idea de la guerra. Cultura Popular se puso en contacto con todos los centros educativos para que los alumnos participaran en la exposición. Un tribunal, presidido por Josep Renau --entonces director general de Bellas Artes-- y compuesto por León Felipe, Salvador Bartolozzi, Antonio Robles, Emilia Elías y José Manaut Viglietti, se encargó de seleccionar los mejores trabajos para celebrar la exposición. En 2008, con motivo de la exposición En defensa de la Cultura, organizada por la Universitat de València y comisariada por Edelmir Galdón, se rescataron los 15 mejores dibujos que se conservaban en la Biblioteca de la citada institución.

El que obtuvo el primer premio tenía la firma de Manolito Hernández, de 9 años, el mismo que con los años se consagraría como Miguel Hernández Mompó. La exposición fue inaugurada el 15 de mayo de 1937 en la sede de la calle de la Paz. Esta iniciativa tuvo un éxito inusual, de tal suerte que se multiplicaron por todo el territorio concursos de similares características, como fue el caso de Socorro Rojo Internacional de Cataluña y la Delegación Nacional de Colonias Escolares (Galdón, Edelmir, 2008, p. 356).

Otra actividad que destacó fue la Exposición del Libro Antifascista que se celebró con motivo del VII Centenario de la conquista de la ciudad de Valencia por Jaume I. Ésta se celebró en el Ateneo Popular Valenciano y colaboraron Ricard Blasco con la lectura de prosas poéticas y Emili Fornet con una conferencia sobre Jaume I. Cultura Popular publicó además el poemario de Miquel Duran de València Guerra, victòria, demà (Blasco, Ricard, 1979, p.151).

\subsection{Las publicaciones}

Las publicaciones ocuparon una parte importante de la actividad de la sede valenciana. Por un lado, se publicó la revista a finales de 1937 Cultura Popular: boletín de la Central de Valencia, que servía de órgano de difusión de todas las acciones que se llevaban a cabo. Téngase en cuenta que en aquel momento, cuando el Gobierno había abandonado Valencia trasladándose a Barcelona, Teresa Andrés debía ser ya delegada del Ministerio de Instrucción Pública y Bellas Artes en Valencia y que, además, la Oficina de Adquisición de Libros y Cambio Internacional, órgano central del sistema bibliotecario, se encontraba en la misma ciudad liderada por María Moliner.

Por lo tanto, aun habiéndose trasladado el Gobierno a Barcelona, la capitalidad del sistema bibliotecario seguía teniendo la sede en Valencia. 
Por otro lado, se imprimieron diferentes materiales para distribuirlos de manera masiva. Se puede distinguir dos grandes tipos de publicaciones que empleó Cultura Popular para difundir sus logros:

a) Carteles y hojas volantes: se conservan carteles de la organización en los que publicitaban sus diferentes actividades, de tal manera que indicaban los periódicos repartidos, las bibliotecas entregadas, etc. El contenido de estos carteles, en general, respondía a datos estadísticos que se empleaban para captar nuevos usuarios. No se trataba de propaganda política, sino de una estrategia de márketing, tema sobre el que Teresa Andrés escribió con posterioridad, dándole una prioridad básica en la creación y mantenimiento de un sistema de lectura pública (Andrés, Teresa, 1945a).

b) Folletos: los folletos que publicó pueden separarse en dos grandes grupos, que se definen por el público al que estaban dirigidos. Por un lado, encontramos los que pretenden explicar a los receptores de las bibliotecas cómo deben usarlas o cuáles son las colecciones, es decir, publicaciones con un contenido biblioteconómico entre las que destaca las Indicaciones para la organización de las bibliotecas de frentes, cuarteles y hospitales (1937). Por otro, existen las que explican la actividad de la organización, como es el caso de Realizaciones de la España leal: la sección de Bibliotecas de Cultura Popular: un año de trabajo: julio 1936-julio 1937 (1938), que fue una edición en separata del trabajo que publicó en Tierra Firme (1937). Los folletos solían estar escritos por Teresa Andrés, aunque en algún caso, como este último, no figura su autoría.

\subsection{La actividad bibliotecaria}

\subsubsection{Los trabajos bibliotecarios}

\subsubsection{La clasificación de las bibliotecas}

Teresa Andrés empleó dos criterios diferentes para clasificar las bibliotecas. El primero dependía de su localización física, distinguiendo entre bibliotecas de organizaciones --en las que incluía los partidos políticos, organizaciones sindicales y cualquier agrupación de índole antifascista-- y bibliotecas de guerra --en las que se encontraban las del frente, hospitales, guarderías y cuarteles--. (Andrés, Teresa, 1937a, p. 605). Esta clasificación servía para establecer una diferenciación clara entre las que se enviaban al frente y las que se constituían en la retaguardia.

Uno de los problemas que más angustió a Cultura Popular durante los primeros meses de la guerra fue la pérdida constante de lotes de libros en los hospitales y en los batallones, debida en gran parte a la falta de coordinación. Con la aparición del Comisariado de la Guerra se logró que se controlaran los envíos, ya que se responsabilizaba a alguien de coordinar la gestión.

No obstante, Teresa Andrés (1937b), tras la consolidación de la organización, clasificó las bibliotecas en dos tipos. Las simples y las circulantes. Las primeras se establecían en un lugar u organización determinado. Estaban catalogadas por materias y llevaban un talonario de préstamo. Las segundas estaban pensadas para prestar libros de 
manera individual o de manera colectiva, como podía ser el caso de la biblioteca de una brigada que prestaba a sus batallones.

\subsubsection{Selección de títulos}

Uno de los temas más interesantes de la actividad bibliotecaria de Cultura Popular es la selección de libros que realizan para los envíos de lotes, sobre todo porque se puede llegar a dudar de la profesionalidad de los bibliotecarios que allí trabajaban. Es cierto que fragmentos como el que se ha entresacado de Juan Vicéns de la Llave, en el que se explica que los libros de ideología fascista son eliminados para elaborar pasta de papel, no propician mucho la idea de una selección profesional de los títulos, pero el estudio de la documentación demuestra que se supo trabajar en un momento de carestía con muy buen criterio.

Un ejemplo interesante es la selección de libros que se realizó para $11^{\mathrm{a}}$ División del Frente de Teruel. A petición del Ministerio de Instrucción Pública la sede de Valencia montó 81 cajas-mueble con 4.400 títulos en una semana para esta División, que pagó 16.000 pts. por la dotación de los lotes. La selección se hizo fue la siguiente:

\footnotetext{
Contienen obras políticas de tendencia Frente Popular, obras sociales, clásicas, de autores modernos y contemporáneos, libros de aventuras y didácticos. Van en ellas las mejores obras de autores seleccionadísimos, tales como Dostoiewsky, Gorki, Tchekov, Artzibachev, Andreiev, Zola, Hugo, Stendhal, Queiroz, Walter Scott, Shakespeare, Dickens, Poe, Wilde, Zweig, Mann, Maurois, France, Malraux, Benda, Blasco Ibáñez, Miró, Valle Inclán, Galdós, Machado, García Lorca, etc., etc.

Entre las novelas de aventuras figuran obras de Verne, de Salgari, de Cooper, de Motta, etc. Algunos libros de viajes, tales como 'Hacia el interior del Amazonas', 'En el país de los Soyotos', etc.

Gramáticas, diccionarios de la Lengua, aritméticas, geografías, atlas, ciencias naturales, física, etc., entre los libros didácticos y de Primera Enseñanza.
}

Ante dicha selección merece la pena hacer un par de comentarios. Por un lado, es interesante comprobar que se incorporaban materiales que eran indispensables para la labor que llevaban a cabo los milicianos de la Cultura, en tanto que continuaban enseñando en el frente para combatir el analfabetismo y la incultura. Incluso se añadían materiales en catalán cuando se sabía que en la unidad militar existían valencianos, incluyendo la Ortografia de Carles Salvador (Blasco, Ricard, 1979, p. 153). Por otro, la selección recogía los clásicos de la novelística del XIX y principios del XX, de tal suerte que no se podría decir que imperaba la ideología sobre la profesionalidad.

No obstante, no se debe olvidar que las comisiones de depuración de la lectura, creadas por los sublevados y que actuaron de manera decisiva tras la finalización de la contienda, elaboraron listas con autores cuya lectura prohibieron. Entre ellos destacaban Galdós, Emilia Pardo Bazán, Espronceda, Larra, Juan Valera, Fernando de Rojas, Blasco Ibáñez, Baroja, Miró, Azorín, Valle-Inclán, Balzac, Zola, los Dumas, Víctor Hugo, Dostoiewski, Tolstoi, Gorki o Dickens. Incluso hubo quien se atrevió a prohibir a Goethe (Ruiz Bautista, Eduardo, 2005, p. 407-410). 
La labor de esas comisiones depuradoras de lectura es muy significativa, ya que será la que tildará de esencialmente comunista a cualquiera de las actividades que llevó adelante la organización.

\subsubsection{Las tareas de marketing bibliotecario}

Uno de los aspectos más interesantes de Cultura Popular es la insistencia en dar publicidad a la existencia de la biblioteca y en procurar que los lectores se impliquen en sus actividades. Teresa Andrés (1937b) invitaba, por un lado, a que se anunciase mediante carteles, haciendo uso de una sección en el periódico del batallón o en el periódico mural $\mathrm{y}$, por otro, a que la vida de la biblioteca incidiese en el funcionamiento del colectivo, ya que el interés de los lectores, ya fuera por solicitar nuevos títulos, ya fuera por comentarlos con otros formando un círculo de lectura, era y es la causa de su funcionamiento.

Cultura Popular en todo momento ofrecía su colaboración para enviar carteles anunciando la biblioteca u orientando acerca de de cómo se podían realizar una actividad cualquiera de las enumeradas.

\subsection{El último semestre de 1938: un nuevo impulso en Madrid}

Con el cese en abril de 1938 del ministro Jesús Hernández Tomás, el equipo que formaba la Sección de Bibliotecas del Consejo Central, incluida Teresa Andrés, pasó a una situación administrativa de interinaje que no se resolvió hasta la disolución del organismo en octubre de 1938. Durante esos meses Teresa Andrés firma como secretaria accidental de la Sección. La actividad de Cultura Popular había disminuido.

El nuevo impulso que se realiza en Madrid evidencia las consecuencias del cambio de Gobierno y la evolución del conflicto. Ya no se tratará de distribuir bibliotecas en los frentes, hospitales o cuarteles. Las iniciativas del ministro Jesús Hernández iban eliminándose poco a poco. Pero Cultura Popular en Madrid no deja de trabajar y el 18 de julio de 1938 inaugura la Biblioteca Central de Consulta y Lectura:

Cultura Popular pone en conocimiento de todo el pueblo antifascista que a partir de hoy viernes y en homenaje a la fecha de nuestro 18 de julio, queda abierta al público su Biblioteca Central de Consulta y Lectura, así como un servicio de préstamo de libros, que se entregarán a la simple presentación de un carnet antifascista o de la tarjeta de socio de Amigos de Cultura Popular. El horario fijado es de las once a las trece horas y de las diecisiete a las veintiuna. Dicha Biblioteca consta aproximadamente de unos 25.000 volúmenes, y tanto el lector llano como el medio y el culto hallarán abundante material en consonancia con su formación: desde libros formativos y de interés para la profesión manual, pasando por las diferentes ramas superiores, hasta libros de política y selecta literatura, protegidos con criterio antifascista y escritos en todos los idiomas. En una palabra, cuanto precisa y a cuanto tiene derecho el deseo de cultura del pueblo español ( $A B C, 19.07 .1938$, p. 4).

La biblioteca se instaló en la Residencia de Estudiantes y tuvo un éxito inesperado, ampliándose el horario de atención al público desde las nueve de la mañana hasta las nueve de la noche. En octubre anunciaba que iba a abrir en breve bibliotecas en 
Atocha, Puente de Vallecas, paseo de las Delicias y calle de Velarde $(A B C, 11.10 .1938$, p. 3). La política de resistencia de Negrín afectaba también a la organización.

\subsection{Los Amigos de Cultura Popular}

Una de las novedades de Cultura Popular es la creación de la asociación denominada Amigos de Cultura Popular. Esta organización intentaba reclutar a todos los simpatizantes para que contribuyeran con su cotización o con su trabajo voluntario. Se conocen dos estatutos: unos impresos en Valencia y otros en Madrid, ambos sin fecha de impresión. Los primeros se encuentran más elaborados que los segundos, pero esto no debe llevar a confusión. Con toda probabilidad, los segundos fueron consecuencia de los primeros, que eran demasiado complejos como para ponerlos en práctica.

Aunque los folletos no estén fechados, se puede suponer que el de se imprimieron a finales de 1937 o a principios de 1938. En 1937 aparecen las primeras referencias a Amigos de Cultura Popular. En el caso del impreso en Madrid, se debe considerar que en diciembre de 1937 se anunciaba que la Central de Madrid se había trasladado a la Residencia de Estudiantes, calle Pinar $n^{\circ} 7$ (Cultura Popular, $n^{\circ}$ 2, diciembre 1937, p. 3), y en el folleto ya aparece esta dirección. En el caso del impreso en Valencia, la dirección que consta de la Central de Madrid es Sacramento, $\mathrm{n}^{\circ}$ 1, que corresponde a la anterior sede, lo que lleva a concluir que se imprimió antes de realizarse el traslado en noviembre o diciembre de 1937. En ambos folletos, la prelación de las direcciones responde a un criterio territorial: aunque figuran las de las dos centrales, en el de Madrid figura antes ésta y después la de Valencia, y al revés sucede en el otro caso.

Los puntos del primer Estatuto son los siguientes:

$1^{\circ}$. Esta Asociación se constituye con el objetivo de extender y cooperar a la obra de difusión cultural que realiza CULTURA POPULAR entre todo el pueblo antifascista.

$2^{\circ}$. Podrán pertenecer a esta Asociación todas las personas o entidades antifascistas, cualquiera que sea su residencia o nacionalidad.

$3^{\circ}$. Para el mejor funcionamiento y enlace, se agruparán los Amigos según su lugar de residencia, reunión o trabajo, eligiendo a uno de ellos para la tarea coordinadora y de relación con la Central de «Amigos de la Cultura Popular», sin perjuicio de lo cual, y cuando se crea conveniente, podrá sustituir a dicha persona una Comisión.

$4^{\circ}$ La colaboración de los Amigos se realizará:

a) Por medio de una cotizaciçon mensual voluntaria.

b) Por la propagación de sus fines.

c) Por la aportación personal de trabajo.

Con estas colaboraciones se coordinará y acrecentará su eficacia. 
$5^{\mathrm{o}}$. Los grupos de Amigos recibirán gratuitamente los Boletines, informes y publicaciones de CULTURA POPULAR, de cuya obra total pueden considerarse colaboradores directos, presentando iniciativas y cooperando en su orientación (Amigos de Cultura Popular de Madrid, 1938).

Las normas de funcionamiento se ceñían a cinco puntos básicos que servían para definir con claridad sus objetivos. En el mismo folleto de estos estatutos se añadían unas instrucciones para el funcionamiento de los grupos, de tal suerte que se indicaba la necesidad de elegir un responsable para que se hiciese cargo tanto de controlar el pago de las cuotas como de reunir el grupo como mínimo una vez al mes. También se sugería la conveniencia de contactar diariamente con la Sección de Amigos de Cultura Popular en la Central para subsanar las dificultades que se iban presentando.

Con la creación de Amigos de Cultura Popular se logró que los recursos materiales que se necesitaban para llevar adelante la organización --como era el caso de la adquisición de títulos-- se costeasen de manera autónoma, eliminando las partidas presupuestarias que se obtenían del Ministerio de Instrucción Pública y Bellas Artes. La recaudación de las cuotas y el trabajo voluntario permitieron dar un nuevo impulso a Cultura Popular.

\section{El papel de Teresa Andrés}

El testimonio de Concha Zardoya señala que Teresa Andrés no se encargaba de la Sección de Bibliotecas de Cultura Popular en enero de 1937. Este dato significativo podría servir para desmontar un pretendido mito: Teresa Andrés había sido el motor de la organización en sus momentos iniciales, desentendiéndose de ésta a medida que asumía cargos en el Ministerio de Instrucción Pública. No obstante, aunque no dirigiese de manera directa la Sección de Bibliotecas de Cultura Popular, cabe replantearse su función en otros niveles más organizativos.

Por un lado, una de las características más remarcables de Teresa Andrés era su obsesión en la formación de profesionales que pudiesen responder a las espectativas de un sistema de lectura pública. Un buen ejemplo es la organización junto a María Moliner de un curso para encargados de biblioteca en 1938, cuando funcionaba a pleno rendimiento la Sección de Bibliotecas del Consejo Central de Archivos, Bibliotecas y Tesoro Artístico.

En el inicio de la andadura de Cultura Popular ya se indicaba que se habían formado grupos de catalogadores que formaban a los que se encargaban de las bibliotecas en las organizaciones políticas y sindicales. Esta tarea iba encaminada a capacitar al personal para el desempeño de las tareas. Debe tenerse en cuenta que Concha Zardoya se desplazó a Valencia en enero de 1937 para asistir a un curso de formación biblioteconómica. Según constaba en el artículo de 3 de enero del mismo año aparecido en el diario Verdad, el Ministerio de Instrucción Pública y Bellas Artes había dado facilidades a la organización para que capacitase a sus trabajadores. 
Es evidente que el trabajo bibliotecario de Cultura Popular nunca rebajó su calidad, lo que obliga a pensar que las personas encargadas tenían una formación que les permitía seguir las directrices que ella había marcado desde el comienzo. Concha Zardoya, por ejemplo, no pertenecía al colectivo de bibliotecarios, ni había trabajado en un establecimiento de tales características hasta su llegada a Valencia. En noviembre de 1937 figura como responsable de la Sección de Bibliotecas de Cultura Popular de la Central de Valencia (Cultura Popular, $\mathrm{n}^{\circ}$ 1, noviembre 1937). Es decir, Teresa Andrés se preocupó por la capacitación de los cuadros que estaban trabajando y tomando decisiones en la organización.

Por otro lado, Teresa Andrés con la aceptación de la Secretaría de la Sección de Bibliotecas del Consejo Central de Archivos, Bibliotecas y Tesoro Artístico logró coordinar todos los esfuerzos que se estaban realizando en materia de lectura pública. Si bien es cierto que, como se podrá observar, el Plan de Bibliotecas de María Moliner se intenta implantar a rajatabla, invirtiendo sumas considerables en la creación de una estructura estable de lectura pública, también es cierto que el ámbito de actuación de Cultura Popular se ceñía a una realidad coyuntural que la guerra había provocado. Otras iniciativas del Ministerio, como las Milicias de la Cultura, habían nacido con perspectivas semejantes.

Lo que logró Teresa Andrés fue coordinar todos esos esfuerzos para que no cayesen en saco roto. La Sección de Bibliotecas era la responsable de la política bibliotecaria del Gobierno y cualquier proyecto de estas características tenía que pasar por sus manos. Como ya se ha comentado, el Ministerio recibía solicitudes para montar bibliotecas del Ejército y con toda seguridad ella las derivaba para Cultura Popular. No debe extrañarnos que Teresa Andrés considerase un hito lograr que el Comisariado de Guerra se hiciese cargo de encauzar las iniciativas de Cultura Popular (Andrés, Teresa, 1937, p. 605). Pero tampoco se debe obviar que Teresa Andrés, como responsable del Ministerio, visaría las bibliotecas que se enviaban, lo que nos lleva a plantear una continuidad en su trabajo con Cultura Popular, en tanto que controlaba su actividad. No es extraño, pues, que en el segundo fascículo de Cultura Popular: boletín de la Central de Valencia apareciese una biografía suya.

\section{Bibliografía}

AGENCE ESPAGNE (1937a): «4326 bibliothéques nouvelles en Espaigne Republicaine». Informations thélegraphiques et téléfoniques de derniere heure, 18 janvier 1937.

AGENCE ESPAGNE (1937b): «L'organisation culturelle “Cultura Popular” vient d'avoir sa Maison Centrale .à Valence». Informations thélegraphiques et téléfoniques de derniere heure, 30 mars 1937.

ÁLVAREZ LOPERA, José (1982): La política de bienes culturales del Gobierno republicano durante la guerra civil española. Madrid, Ministerio de Cultura. 2 v.

AMIGOS DE CULTURA POPULAR DE MADRID (1938): Estatutos de Amigos de Cultura Popular. Madrid, Imp. La Rafa.

AMIGOS DE CULTURA POPULAR DE VALENCIA (1937): Grupos de amigos de Cultura Popular: normas de su funcionamiento. Valencia, J. Melià. 
MEI, II, Vol. 2, nº 2, pág. 153

ANDRÉS ZAMORA, Teresa (1937): «Cultura Popular y su Sección de Bibliotecas» en:Un año de labor cultural de la República española (julio 1936-julio 1937). Es un suplemento de Tierra firme (1936), año II, $\mathrm{n}^{\circ}$ 3-4, p. 604-606. Se editó también como separata en 1938 bajo el título Realizaciones de la España leal: la Sección de Bibliotecas de Cultura Popular: una año de trabajo julio 1936-julio 1937. Valencia, Cultura Popular.

ANDRÉS ZAMORA, Teresa (1938): Indicaciones para la organización de Bibliotecas de Frentes, Cuarteles y Hospitales. Valencia, Cultura Popular.

ANDRÉS ZAMORA, Teresa (1945a): «Las bibliotecas generales en España». Boletín de la Unión de Intelectuales Españoles. Año II, $\mathrm{n}^{\circ}$ 4, marzo.

AZNAR SOLER, Manuel (2008): «La política cultural del Ministerio de Instrucción Pública y Bellas Artes (1936-1937)» en: En defensa de la cultura: Valencia, capital de la República (1936-1937). València, Universitat de València: 42-63

AZNAR SOLER, Manuel; PÉREZ I MORAGÓN, Francesc (2008): «Entrevista a Emili Gómez Nadal» en: GÓMEZ NADAL, Emili: Diaris i records. València, Universitat de València: 369-413.

BLASCO, Ricard (1979): «El valencianisme cultural durant la Guerra Civil (1936-1939)». L'Espill, nº 1 -2, p. 95-169.

CULTURA POPULAR (1937): «Cultura Popular». Verdad, 03.01.1937, p. 2.

GALDÓN, Edelmir (2008): «Crónica de un año decisivo» en: En defensa de la cultura: Valencia, capital de la República (1936-1937). València, Universitat de València: 246-443.

GARCÍA EJARQUE, Luis (2000): Historia de la lectura pública en España. Gijón, Trea.

NAVARRO, Francisco Javier (2002): Ateneos y grupos ácratas: vida y actividad de las asociaciones anarquistas valencianas durante la Segunda República y la Guerra Civil. Valencia, Biblioteca Valenciana.

PÉREZ MORAGÓN, Francesc (2008): «En el país, en la lengua del país» en: Libros en el infierno 1939: la Biblioteca de la Universidad de Valencia. València, Universitat de València, p. 143-173.

RENAU, Josep (2007): «Notas el margen de Nueva cultura» en Nueva cultura [cederón]. Valencia, Faximil Ediciona Digitals.

RODRÍGUEZ-MOÑINO, Rafael (2002): La vida y obra del bibliófilo y bibliógrafo extremeño D. Antonio Rodríguez-Moñino. $2^{\text {a }}$ ed. Madrid, Beturia.

RUIZ BAUTISTA, Eduardo (2005): Los señores del libro: propagandistas, censores y bibliotecarios en el primer franquismo. Gijón:, Trea.

SALABERRÍA, Ramón (2002a): «Las bibliotecas populares en la correspondencia de Juan Vicéns a Lulu Jourdain y Hernando Viñes (1933-1936) ». Anales de Documentación, nº 5: 309-332.

SALABERRÍA, Ramón (2002b): «La larga marcha de Juan Vicéns (Zaragoza,1895 - Pekín,1959)» en: VICÉNS DE LA LLAVE, Juan: España viva: el pueblo a la conquista de la cultura. Madrid, Vosa, Asociación Educación y Bibliotecas.

SEGUÍ I FRANCÈS, Romà (2008):«Don Antonio Rodríguez-Moñino en la Valencia de la guerra civil (1937-1939): el itinerario de un intelectual comprometido con la causa republicana» en: En defensa de la cultura: Valencia, capital de la República (1936-1937). València, Universitat de València, p. 134-165. de la culture publicado en París en 1938. 
MEI, II, Vol. 2, nº 2, pág. 154

VICÉNS DE LA LLAVE, Juan (2002): España viva: el pueblo a la conquista de la cultura. Madrid, Vosa, Asociación Educación y Bibliotecas. Es la traducción de su libro L'Espagne vivant: le peuple à la conquête de la culture publicado en París en 1938.

ZARDOYA, Concha (2002): «José Manaut Viglietti y "Cultura Popular"» en: José Manaut: óleos y dibujos desde la prisión, 1943-1944. Valencia, Universitat de valència, Universidad Carlos III de Madrid: 20-25. 